\title{
Cytotoxicity and Cancer (HeLa) Cell Killing Efficacy of Aqueous Garlic (Allium sativum) Extract
}

\author{
M. S. Islam, Y. Kusumoto*, and M. Abdulla Al-Mamun \\ Department of Chemistry and Bioscience, Graduate School of Science and Engineering, Kagoshima \\ University, 1-21-35 Korimoto, Kagoshima 890-0065, Japan
}

Received 26 November 2011, accepted in revised form 20 January 2011

\begin{abstract}
Garlic (Allium sativum) is a herb that is used mainly as a food in many countries for its medicinal properties since ancient times. It enhances immune functions and has antibacterial, antifungal, antivirus and anticancer activities. Organosulfur compounds originating from garlic inhibit carcinogen activation. In this study we prepared aqueous garlic extract (AGE) and its in vitro application to cancer (HeLa) cell line was performed to observe the cancer cell killing efficacy. Different concentrations of AGE like 100, 200, 300, 400 , and $500 \mu \mathrm{L}$ per a $5-\mathrm{mL}$ minimum essential medium solution were used for treatment. The results revealed that $95 \%$ cancer cells were destructed in a dose of $500 \mu \mathrm{L}$, whereas about 92, 87, 60, and $24 \%$ cancer cells were destructed in a dose of $400,300,200$ or $100 \mu \mathrm{L}$ of AGE, respectively.
\end{abstract}

Keywords: Aqueous garlic extract; Cancer cells; Cytotoxicity; Anticancer activity.

(C) 2011 JSR Publications. ISSN: 2070-0237 (Print); 2070-0245 (Online). All rights reserved. doi:10.3329/jsr.v3i2.6557

J. Sci. Res. 3 (2), 375-382 (2011)

\section{Introduction}

Medicinal properties of garlic (Allium sativum) have been widely known and used since ancient times and is probably the oldest and most consumed plant medicine known and it possesses multiple beneficial effects such as antimicrobial, hypolipidemic, antithrombotic, and antitumor activities [1] and used by different cultures. Anticancer properties of garlic were first described by Weisberger and Pensky in 1958. They reported an inhibitory effect of a garlic extract on cancer cell growth both in vitro and in vivo [2]. Medicinal properties of garlic and other representatives of the family Allium (onion, shallot), including their anticancer efficacy, have been attributed to organosulfur compounds. The different health benefits of garlic are attributed to its sulfur-containing constituents. These are classified as

*Corresponding author: kusumoto@sci.kagoshima-u.ac.jp 
oil-soluble and water-soluble compounds. Oil-soluble compounds include diallyl sulfide, diallyl disulfide, and diallyl trisulfide, allyl methyl trisulfide, dithiins, and ajoene. The most important initial sulfur compound occurring in the intact garlic bulbs is alliin (Sallylcysteine sulfoxide). The whole bulbs contain also $\gamma$-glutamyl-S-allylcysteine, Smethylcysteine sulfoxide (methiin), Strans-1-propenylcysteine sulfoxide, S-2carboxypropylglutathione and S-allylcysteine, though they are at much smaller amounts [3]. The reactions of allicin with - $\mathrm{SH}$ groups can yield S-allylcysteine or Sallylmercaptocysteine that are water soluble compounds [4]. Unlike oily sulfur compounds, water-soluble compounds are odorless and have more delicate and less characteristic flavor [5]. These compounds are also formed during aqueous garlic extraction, when the initial compound $\gamma$-glutamyl-S-allylcysteine is transformed into Sallylcysteine and this reaction is catalyzed by $\gamma$-glutamyltranspeptidase $(\gamma \mathrm{GT})$ (Scheme 1). S-allylcysteine along with its derivatives, S-methylcysteine and S-allylcysteine, are components of aqueous extracts of garlic and possess biological activity both in vitro and in vivo [6].

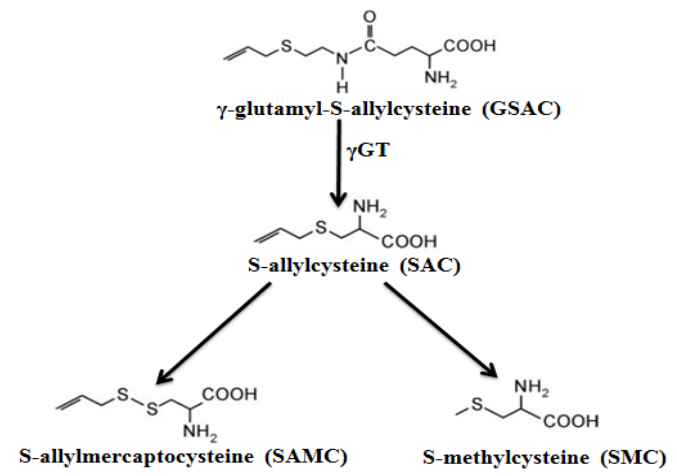

Scheme 1. Formation of water-soluble garlic-derived organosulfur compounds from $\gamma$-glutamyl-Sallylcysteine. $\gamma \mathrm{GT}$ : $\gamma$-Glutamyltranspeptidase.

Intact garlic cloves contain also steroidal saponins [7] and organic selenium compounds that possess a potential anticancer efficacy [8]. The main selenium compound is $\gamma$-glutamyl-S-methylselenocysteine. Like its sulfur analog $\gamma$-glutamyl-S-allylcysteine, $\gamma$ glutamyl-S-methylselenocysteine can be transformed by $\gamma \mathrm{GT}$ to other selenium derivatives, e.g., S-methylselenocysteine. Comparative studies of chemopreventive efficiency of organoselenium compounds and their sulfur analogs demonstrated that diallyl selenide was 300-fold more effective than diallyl sulfide in protecting against 7 , 12-dimethylbenz[ $\alpha$ ]anthracene-induced mammary adenocarcinomas in rats [9]. It is well known that both oil-soluble and water-soluble organosulfur compounds are contained in garlic and onions. Some of these have been shown to be chemopreventive in animal models of carcinogenesis. For example, diallyl sulfide inhibits development of colon carcinomas, esophageal carcinomas, pulmonary adenomas, and forestomach tumors in rodents when administered prior to carcinogen exposure [10-13]. Since then intensive 
laboratory and epidemiological studies have been carried out to verify chemopreventive and anticarcinogenic effects of Allium sativum, and to explain mechanisms of its action [6]. We prepared the garlic extract for the first time solely using distilled water as solvent and our study is focused on anticancer efficacy of the aqueous extract of garlic on the properly cultured cervical carcinoma (HeLa) cell line using different concentrations.

\section{Materials and Methods}

\subsection{Preparation of aqueous garlic extracts (AGE)}

Fresh raw garlic (Allium sativum) was purchased from local market of Kagoshima city, Japan and was identified by Professor Tsuyoshi Yoneda (Faculty of Agriculture, Kagoshima University, Japan) where its voucher specimen (No. AS0049) was deposited. Cloves from fresh raw garlic were chopped and ground and were made fine paste. Then the garlic paste was weighted and it was $200 \mathrm{~g}$. That paste was soaked in $250 \mathrm{ml}$ distilled water and then magnetically stirred for 3hours. Finally AGE was collected by filtration over whole day and we got AGE with a final concentration of $150 \mathrm{mg} / 200 \mathrm{~mL}$. Thereafter AGE was kept undisturbed for further use in cancer cells.

\subsection{Cell culture}

HeLa cells were provide by the RIKEN BRC through the National Bio-Resource Project of the MEXT, Japan and stored in liquid $\mathrm{N}_{2}$ to ensure the best quality. The mentioned cancer cell line was cultured in a minimum essential medium (MEM) solution with $10 \%$ newborn calf serum (NBS) in a humidified incubator with an atmosphere of $5 \% \mathrm{CO}_{2}$ in air at $37^{\circ} \mathrm{C}$ and the cells were plated at a concentration of about $3 \times 10^{5}$ in $60 \mathrm{~mm}$ Petri dishes and allowed to grow for 3 days. For HeLa cell culture, phosphate buffer saline (PBS, Invitrogen Corporation, Gibco), enzyme Trypsine-EDTA (Gibco) solution, dye trypan blue (Nacalai Tesque, Inc., Kyoto, Japan) were purchased and used. Monolayer cultures of cancer cell line (HeLa Cells) were maintained as described by Abdulla-AlMamun et al. [14].

\subsection{In vitro cytotoxicity and anticancer assay}

The in vitro cytotoxicity and anti-cancer effect of AGE against the HeLa cell line was evaluated by trypan blue exclusion method [14]. Cancer cell viability was examined by treating with AGE solution for $24 \mathrm{~h}$ incubation in an incubator. To investigate the cytotoxicity and anticancer efficacy of AGE, one dish was used as control without garlic extract solution and the other five dishes were treated with different concentrations, like 100, 200, 300, 400 and $500 \mu \mathrm{L}$ of AGE solution per $5 \mathrm{~mL}$ of MEM solution. The light power was measured by a spectro-radiometer (Model: LS-100, EKO Instrument Co. Ltd.) and the images were taken using an Olympus inverted CKX41 microscope with a 
numerical light field condenser (N.A.0.3), which delivers a very narrow beam of white light from tungsten lamp (6V, 30W halogen illumination) on top of the sample.

Table 1. Viable cancer cell counting after treated by AGE at different concentrations.

\begin{tabular}{|c|c|c|c|c|c|c|}
\hline \multirow[t]{2}{*}{ Treatment } & \multicolumn{4}{|c|}{ Viable cell counting } & \multirow[t]{2}{*}{ Average } & \multirow[t]{2}{*}{ In percent } \\
\hline & $1^{\mathrm{st}}$ & $2^{\text {nd }}$ & $3^{\text {rd }}$ & $4^{\text {th }}$ & & \\
\hline Control & 39 & 40 & 42 & 39 & 40 & $100^{\mathrm{a}}$ \\
\hline $100 \mu \mathrm{L}$ & 35 & 34 & 28 & 24 & 30 & 76 \\
\hline $200 \mu \mathrm{L}$ & 14 & 17 & 20 & 13 & 16 & 40 \\
\hline $300 \mu \mathrm{L}$ & 15 & 6 & 4 & 5 & 5 & 13 \\
\hline $400 \mu \mathrm{L}$ & 3 & 3 & 5 & 2 & 3 & 8 \\
\hline $500 \mu \mathrm{L}$ & 2 & 1 & 2 & 3 & 2 & 5 \\
\hline
\end{tabular}

${ }^{a}$ Average number of cells counted in control (40) is considered as $100 \%$..

A haemocytometer was used to estimate the total number of viable cells (by counting cells in the four $1 \mathrm{~mm}^{2}$ corners of the hemacytometer) and average number of the cells per unit volume ( $\mathrm{mL}$ ) of medium was calculated as the sum of the counted cell number/ $3 \times 10^{5}$ (Table 1$)$.

\section{Results}

Numerous studies have suggested that garlic possesses anticancer activity. Garlic extracts were prepared by soaking of sliced garlic cloves in extracting solution for a specific time. Then, after separation of the solution the extract was concentrated and was used to find the cytotoxicity and cancer cell killing efficacy. We evaluated AGE cytotoxicity and anticancer efficacy against HeLa cell viability and proliferation using direct cell counts by trypan blue staining. One hundred to $500 \mu \mathrm{L}$ of AGE significantly reduced the viability of HeLa cells (Fig. 1).

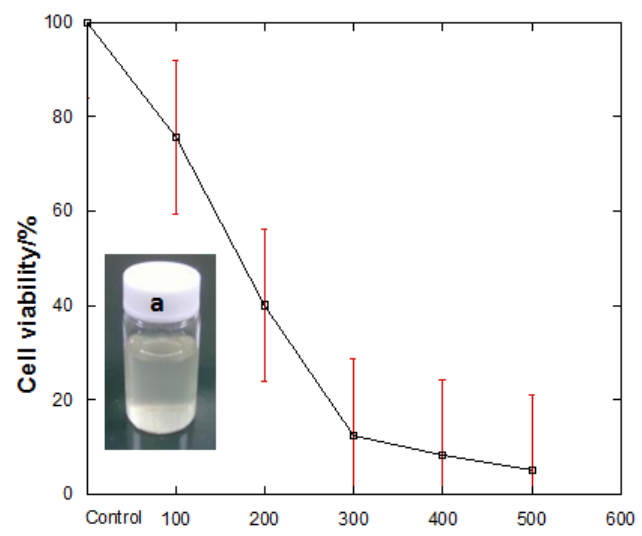

Aqueous Garlic Extract Solution / $\mu \mathrm{L} / 5 \mathrm{~mL}$ MEM

Fig. 1. Effects of AGE on viability and proliferation of HeLa cells. Cell viability was assessed by trypan blue dyeing assays for $24 \mathrm{~h}$ after treatment with the indicated concentrations of AGE. 
As shown in Fig. 1, the percentage of viable cells remained more than $75 \%$ even when cells were treated with $100 \mu \mathrm{L}$ of AGE for $24 \mathrm{~h}$. But when the doses were increased, the percentages of viable cells were decreased and finally at a dose of $500 \mu \mathrm{L}$ of AGE only $5 \%$ cells were viable. These results indicate that AGE shows significant potentiality against the viability and proliferation of cervical carcinoma cell (HeLa cell) line.

\section{Discussion}

Studies of recent years have focused on elucidation of the mechanism of biological activity of garlic. Hundreds studies were conducted both in vivo and in vitro using individual organic sulfur compounds, mostly allyl sulfides and their metabolites or watersoluble compounds, S-allylcysteine and S-allylmercaptocysteine [15-17]. Accumulating evidence indicates that various food ingredients may play an essential role in colon cancer prevention. The AGE used in this study is an extract of fresh garlic that is aged over a prolonged period and contains water-soluble allyl amino acid derivatives, which account for most of its organosulfur content, stable lipid-soluble allyl sulfides, flavonoids, saponins, and essential macro- and micronutrients [18].
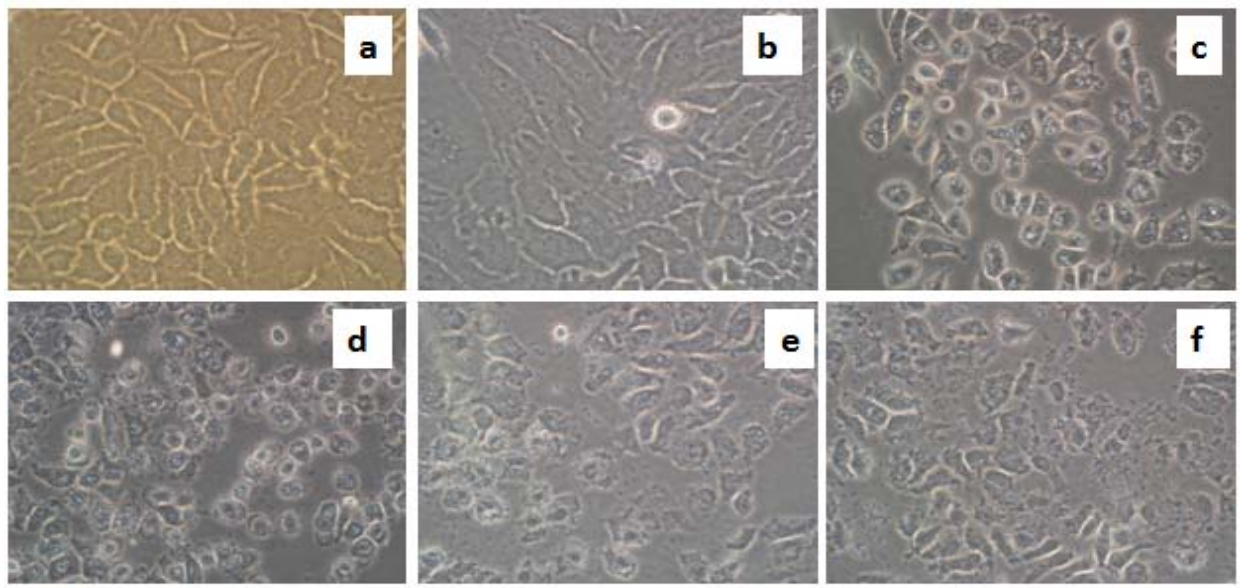

Fig. 2. Microscopic images of HeLa cells after $24 \mathrm{~h}$ incubation; cells without (a) any treatment (control), with (b) $100 \mu \mathrm{L}$, (c) $200 \mu \mathrm{L}$, (d) $300 \mu \mathrm{L}$, (e) $400 \mu \mathrm{L}$, and (f) $500 \mu \mathrm{L}$ of AGE/ 5mL MEM.

Fig. 2(a)-(f) show microscopic images of HeLa cells after $24 \mathrm{~h}$ incubation only in MEM medium (control dish), 100, 200,300, 400 and $500 \mu \mathrm{L}$ of AGE / $5 \mathrm{~mL}$ of MEM, respectively. It is obvious that AGE has a significant affect against the HeLa cell line because $95 \%$ of cancer cells were found to be dead after $24 \mathrm{~h}$ incubation with a dose of $500 \mu \mathrm{L}$ of AGE / $5 \mathrm{~mL}$ of MEM (Fig. 1). According to the available literature, the following mechanisms may be involved in the chemopreventive effects of organosulfur 
compounds: (i) Enhancement of the activity of specific mixed-function oxidases that depress the activation of carcinogens [19, 20, 21], (ii) induction of phase II enzymes that enhance detoxification and excretion of potential carcinogens and reduction of the formation of DNA adducts [22], (iii) increased synthesis of glutathione, an endogenous tripeptide thiol that directly protects cells from damage by free radicals and (iv) apoptosis induction in cancer cells [23]. Allicin (diallyl thiosulfinate) which is the main biologically active compound derived from garlic and easily diffuses through cell membranes, exerts its biological effects by reacting with free thiols within the cell. In living cells, reduced glutathione (GSH) is the major free thiol participating in cellular redox reactions and mixed disulfide formation. GSH is therefore the main cellular target of allicin reaction (Scheme 2) [24].

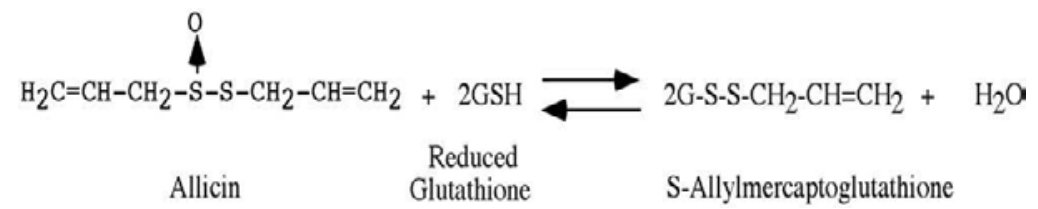

Scheme 2. Formation of S-allylmercapto-glutathione.

However, its main oxidation products, S-allylmercapto-glutathione and Sallylmercapto-cysteine, could exert their action in more remote sites within the body because they are more stable. Thiol-disulfide exchange reaction can occur between protein sulfhydryl groups and S-cysteinyl compounds from garlic, such as S-allylmercaptocysteine (reaction 1).

$$
\text { Allyl-SS-Cys + protein-SH } \rightarrow \text { Protein-S-S-Cys + allyl-SH }
$$

It is well known that reactive oxygen species fulfill a regulatory role in the cell, while reversible S-thiolation can be considered to be a regulatory redox mechanism for cellular processes. Pinto et al. have suggested that such S-cysteinylation of signaling proteins and transcription factors may be a primary target for development of chemopreventive or therapeutic agents that stimulate pro-apoptotic proteins or inactivate oncogenic factors [25]. Through these citations, our experimental evidence proof the efficacy of garlic extract against the carcinoma cells line. Although great majority of studies devoted to anticancer action of garlic-derived organosulfur compounds were conducted in vitro but all the reports say that they used ethanol extract and the important fact that ethanol itself cytotoxic, whereas we first prepared and used the aqueous garlic extract to the best of our knowledge. Finally, our experimental results are the clear evidence of cytotoxicity that was firmly effective against the HeLa cell line.

\section{Conclusion}

We prepared aqueous garlic extract (AGE) for the first time to the best of our knowledge and the synthesized AGE showed a significant efficacy against cervical carcinoma cell 
(HeLa cell) line with different concentrations along with 95\% cell killing potentiality in a maximum dose of $500 \mu \mathrm{L}$ of AGE / $5 \mathrm{ml}$ of MEM. So, it may be concluded that AGE preserves the high potentiality against the HeLa cell line but further study is suggested to observe any adverse effect in normal cells.

\section{Acknowledgement}

The present work was partly supported by Grant-in-Aid for Scientific Research (B) (No.19360367) from Japan Society for the Promotion of Science (JSPS). The authors are very thankful to Professor Tsuyoshi Yoneda, Faculty of Agriculture, Kagoshima University, Japan for identification of the plant.

\section{References}

1. K. T. Augusti, Ind. J. Exp. Biol. 34, 634 (1996).

2. A. S. Weisberger, J. Pensky, Cancer Res. 18, 1301 (1958).

3. H. Amagase, J. Nutr. 136, 716 (2006).

4. A. Rabinkov, T. Miron, D. Mirelman, M. Wilchek, S. Glozman, E. Yavin, and L. Weiner, Biochim. Biophys. Acta 1499, 144 (2000). doi:10.1016/S0167-4889(00)00119-1

5. Y. Kodera, A. Suzuki, O. Imada, S. Kasuga, I. Sumioka, A. Kanezewa, N. Taru, M. Fujikawa, S. Nagae, K. Masamoto, K Maeshige, and K. Ono, J. Agric. Food Chem. 50, 622 (2002). doi:10.1021/jf0106648

6. I. Małgorzata, K. Inga, W. Lidia, Envirn. Mol. Mutagen. 50, 247 (2009). doi:10.1002/em.20474

7. V. Lanzotti, J. Chromatogr. A. 1112, 3 (2006). doi:10.1016/j.chroma.2005.12.016

8. I. Arnault, J. Auger, J. Chromatogr. A. 1112, 23 (2006). doi:10.1016/j.chroma.2006.01.036

9. K. El-Bayoumy, R Sinha, J. T. Pinto, R. S. Rivlin, J. Nutr. 136, 864 (2006).

10. M. J. Wargovich, Carcinogenesis 8, 87 (1987). doi:10.1093/carcin/8.3.487

11. M. J. Wargovich, C. Woods, V. W. S. Eng, L. C. Stephens, K. Gray, Cancer Res. 48, 6872 (1988).

12. L. W. Wattenberg, V. L. Sparnins, G. Barany, Cancer Res. 49, 2689 (1989).

13. V. L. Sparnins, G. Barany, L. W. Wattenberg, Carcinogenesis 9, 131 (1988). doi:10.1093/carcin/9.1.131

14. M. Abdulla-Al-Mamun, Y. Kusumoto, A. Mihata, M. S. Islam, B. Ahmmad, Photochem. Photobiol Sci. 8, 1125 (2009). doi:10.1039/b907524k

15. M. Thomson, M. Ali, Curr. Cancer Drug Targets. 3, 67 (2003). doi:10.2174/1568009033333736

16. A. Herman-Antosiewicz, S. V. Singh, Mutat. Res. 555, 121 (2004). doi:10.1016/j.mrfmmm.2004.04.016

17. A. Herman-Antosiewicz, A. A. Powolny, S. V. Singh, Acta Pharmacol. Sin. 28, 1355 (2007). doi:10.1111/j.1745-7254.2007.00682.x

18. H. Amagase, Intake of garlic and its components. Nutritional and Health Benefits of Garlic as a Supplement Conference, Newport Beach, CA, p. 4 (abs), (1998).

19. J. F. Brady, H Ishizaki, J. M. Fukuto, M. C. Lin, A. Fadel, J. M. Gapac, and C. S. Yang, Chem. Res. Toxicol. 4, 642 (1991). doi:10.1021/tx00024a008

20. H. W. Chen, C. W. Tsai, J. J. Yang, C. T. Liu, W. W. Kuo, and C. K. Lii, J. Nutr. 89, 189 (2003). doi:10.1079/BJN2002766

21. M. M. Reicks, D. L. Crankshaw, Nutr Cancer 25, 241 (1996).

doi:10.1080/01635589609514448 


\section{Cytotoxicity and Cancer}

22. D. Guyonnet, C. Belloir, M. Suschetet, M. H. Siess, and A. M. Le Bon, Mutat Res. 495, 135 (2001).

23. S. Kweon, K. A. Park, and H. Choi, Life Sci 73, 2515 (2003). doi:10.1016/S0024-3205(03)00660-X

24. T. Miron, M. Wilchek, A. Sharp, Y. Nakagawa, M. Naoi, Y. Nozawa, and Y. Akao, J. Nutri. Biochem. 19, 524 (2008). doi:10.1016/j.jnutbio.2007.06.009

25. J. T. Pinto, B. F. Krasnikov, A. J. L. Cooper, J .Nutr. 136, 835 (2006). 